REPRINTED FROM ANNALS OF OTOLOGY, RHINOLOGY \& LARYNGOLOGY, JANUARY-FEBRUARY 1987

Volume 96, Number 1, Part 2

Supplement 128

COPYRIGHT 1987, ANNALS PUBLISHING COMPANY

\title{
SURGERY FOR THE SAFE INSERTION AND REINSERTION OF THE BANDED ELECTRODE ARRAY
}

\author{
G. M. Clark, PhD, Fracs; B. C. Pyman, DlO, FRaCS; R. L. Webb, Dlo, Fracs; B. K-H. G. Franz, \\ MD, Dip Aud; T. J. Redhead, DLO, FRACS; R. K. ShePherd, BSC, Dip Ed
}

Adhering to the surgical technique outlined in the protocol for the Nucleus implant has resulted in over 100 patients worldwide obtaining significant benefit from multichannel stimulation. A detailed analysis of the results in 40 patients shows that it improves their awareness of environmental sounds and their abilities in understanding running speech when combined with lipreading. In addition, one third to one half of the patients also understand significant amounts of running speech without lipreading and some can have interactive conversations over the telephone. It is clear that any insertion trauma is not significant, which is confirmed by the excellent clinical results.

The Nucleus prosthesis is implanted through the incision shown in Fig lA. This is a modification of our original incision. ${ }^{1}$ The anterior limb is now only extended halfway along the postaural sulcus, because access to the mastoid tip is no longer required.

It was originally considered important to fix the thick proximal electrode in a gutter beneath the cortex of the mastoid tip so that the junctional area between the thick and thin sections would be well protected from any movements from outside likely to cause metal fatigue and stress fractures. It is, however, difficult to tie the stay sutures required to fix the electrode in its groove after the banded array has been inserted into the cochlea, because the assistant surgeon is at the head end of the table. For this reason a gutter is now made superiorly in the mastoid along a line parallel with the supramastoid crest. Although this procedure does not protect the electrode as well from external movements, protection can nevertheless be achieved by fixing it with two stay sutures inserted through two pairs of drill holes positioned as shown in Fig lB. The stay sutures are tied around the thick proximal electrode lead, and the junctional area should be positioned in the aditus to the antrum where it is protected from external pressure. Fixing the electrode superiorly also has advantages in children because there will be smaller growth changes in the region rather than the mastoid tip and therefore less risk of the electrode in the cochlea being pulled out.

The banded electrode array for insertion into the scala tympani of the basal turn of the cochlea is smooth, flexible, free-fitting, and tapered. It can be inserted through the round window, in which case it is important to obtain a good view along this turn by first drilling the anteroinferior bony overhang of the round window niche and then drilling the crista fenestrae. Alternatively, it can be in- serted through a small and separate opening drilled anteroinferior to the round window.

To insure the safe insertion of this banded electrode array, a number of studies were undertaken before the clinical trial of the Nucleus device. Initially, surgical trauma was assessed on 34 cat cochleas implanted with electrodes inserted through the round window, a single opening drilled anteroinferior to the round window, and multiple openings made through the otic capsule into the apical, middle, and basal turns. ${ }^{2-5}$

These studies showed that a free-fitting electrode passed through the round window membrane into the first 6 to 7 $\mathrm{mm}$ of the basal turn resulted in no loss of spiral ganglion cells, as well as the preservation of significant numbers of hair cells. Damage occurred in only one cochlea with this method of insertion. In this case the electrode penetrated the basilar membrane and infection was localized at the basal turn. When an electrode was inserted through an opening drilled directly into the scala tympani, a localized loss of spiral ganglion cells occurred if the electrode caused trauma to the basilar membrane or osseous spiral lamina.

The results emphasized that placing multiple electrodes by drilling directly into the otic capsule at a number of locations should be avoided. On the other hand, a free-fitting electrode, passed along the basal turn through the round window or an opening drilled anterolateral to the round window should result in minimal or no trauma, provided the insertion was gentle and no force was applied after resistance was first experienced.

Surgical trauma was also assessed histologically in a study on nine implanted and five control fresh cadaver temporal bones. The study showed that the electrode insertion is relatively safe and causes minimal or no trauma. ${ }^{6}$

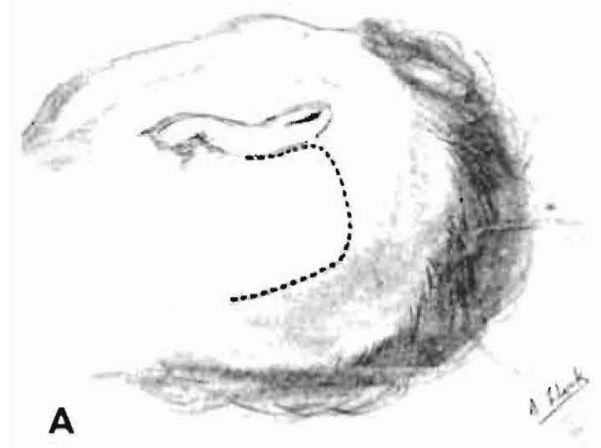

B

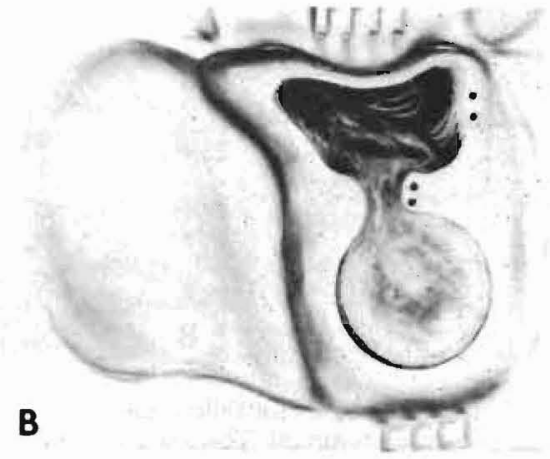

Fig l. Surgical procedure. A) Diagram of modified skin incision for implantation of multichannel cochlear prosthesis. B) Bed created for Nucleus receiver-stimulator, and placement of two pairs of drill holes for stay sutures required to fix thick electrode lead in groove in mastoid bone. 


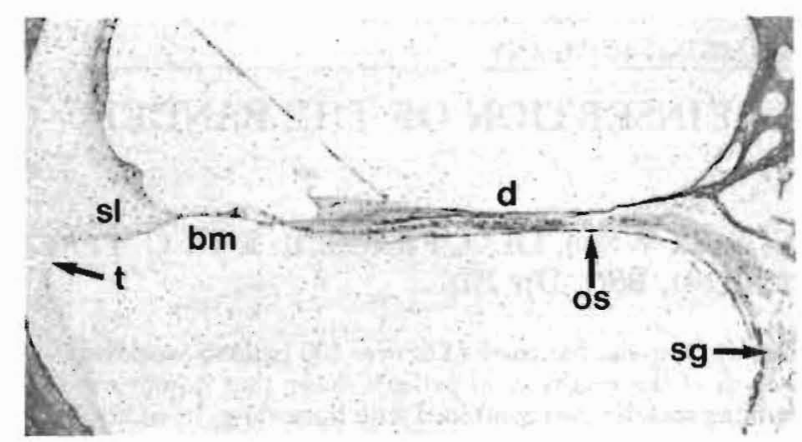

Fig 2. Photomicrograph of tear in spiral ligament in human cochlea after insertion of Nucleus electrode array (original x58), t - tear, sl - spiral ligament, bm - basilar membrane, $\mathrm{d}$ - dendritic nerve fibers, os - osseous spiral lamina, sg - spiral ganglion cells.

The results also showed that if force is applied to the electrode after it first meets resistance, the electrode may cause a localized perforation of the basilar membrane, or alternatively it may buckle just inside the basal turn, resulting in a localized fracture of the osseous spiral lamina or a tear of the basilar membrane close to the round window. There is good evidence that the loss of nerve fibers and spiral ganglion cells associated with these two forms of trauma is limited to the site of the lesion. ${ }^{7-9}$ Because the tears of the basilar membrane represented $3 \%$ of the total insertion length, the lesions would have affected only a small number of the 22 stimulus channels, and therefore would have had a minimal effect on the patient's performance. Furthermore, it was clear from the surgeon's written comments at the time of the insertion that this form of trauma can be avoided if the insertion is stopped when resistance is felt.

Another type of lesion seen in some of the temporal bones was a small localized tear of the spiral ligament. This occurred when the electrode first met the outer wall before it passed around the basal turn. An example of a tear in the spiral ligament is shown in Fig 2. As can be seen, the lesion was small. Furthermore, in our experimental studies on animals we have shown that when an electrode produces a tear in the spiral ligament similar to that found in the human temporal bone insertion study, there is no loss of dendrites or spiral ganglion cells. Figure $3 \mathrm{~A}$ shows photomicrographs from a cat cochlea in which a
Silastic rod with a square end caused a tear in the spiral ligament without the loss of dendrites. Because the cat had been implanted for 6 weeks any significant loss of dendrites would have been apparent (Fig 3B). Consequently, a tear in the spiral ligament seen in our human temporal bone studies would have had no effect on the dendrite or spiral ganglion cell populations.

Tears were also seen in Reissner's membrane in the histological study in the five control and nine implanted bones. The data were analyzed statistically, and the results for the standard $t$ test and Mann-Whitney test showed there was no significant difference between the control unimplanted bones and those implanted with the Nucleus electrode with regard to the number or length of the Reissner's membrane tears.

Surgical trauma was further assessed on surface preparations of nine human temporal bones at the University of Melbourne $^{10}$ and 20 bones at the University of Sydney." These additional studies confirmed that the Nucleus electrode array could be inserted with minimal or no trauma providing the insertion was stopped when resistance was felt.

The relatively safe insertion of the Nucleus electrode is confirmed by the fact that our patients have been implanted with good clinical results. We have also shown in three patients, when the University of Melbourne's prototype device was replaced with the Nucleus clinical trial version, that the Nucleus banded multielectrode array could be removed with ease and another one inserted. This was done without reducing the patient's clinical performances or stimulus thresholds.

Finally, the question of trauma in multichannel cochlear implantations should be seen in perspective and in relation to established surgical procedures such as a stapedectomy. A stapedectomy carried out by a very experienced surgeon will result in $5 \%$ to $10 \%$ of patients not receiving the hoped for benefit, $1 \%$ losing useful hearing, and $0.5 \%$ finishing with a dead ear. By contrast, patients with no useful hearing implanted with the Nucleus prosthesis can expect to obtain significant help when using the device combined with lipreading, and $30 \%$ to $50 \%$ can understand useful amounts of running speech using the prosthesis alone without help from lipreading.

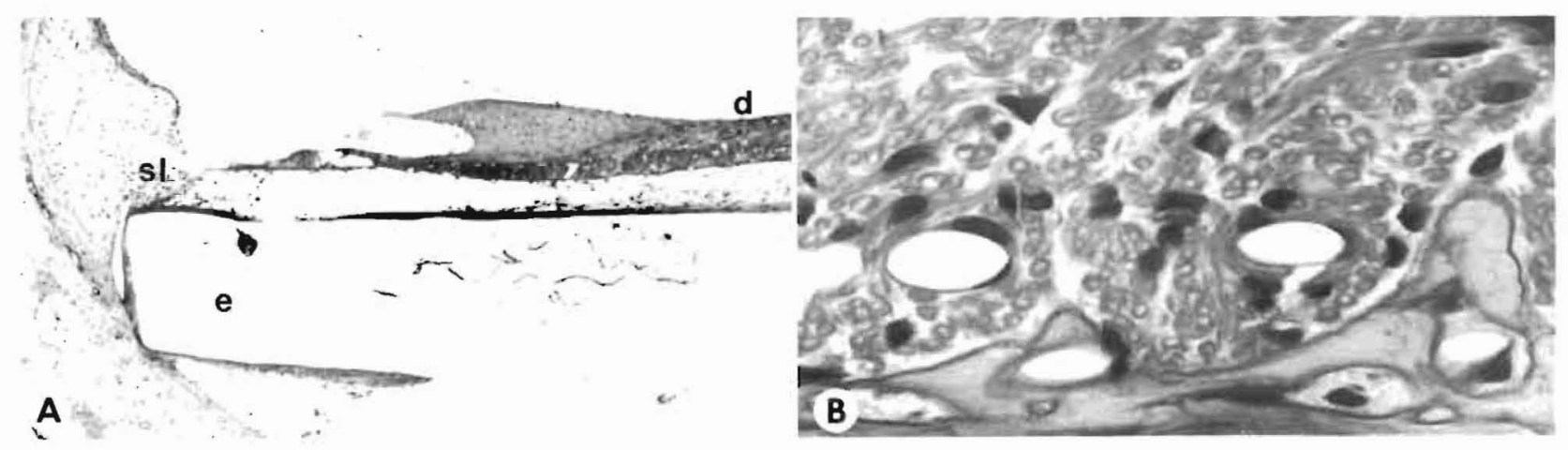

Fig 3. Photomicrographs of cat cochlea showing spiral ligament following trauma from Silastic rod (original x85). A) Healed tear Silastic rod was sectioned in situ, and is shown in scala tympani. There was no loss of dendritic nerve fibers after 6 weeks. sl - spiral ligament, $\mathrm{e}-$ Silastic rod, $\mathrm{d}-$ dendritic nerve fibers. B) High power view of dendrites (original $\mathrm{x} 500$ ). No loss or degeneration is shown. 


\section{REFERENCES}

1. Clark GM, Pyman BC, Webb RL, Bailey QE, Shepherd RK. Surgery for an improved multiple-channel cochlear implant. Ann Otol Rhinol Laryngol 1984;93:204-7.

2. Clark GM. A hearing prosthesis for voice perceptive deafness - experimental studies. J Laryngol Otol 1973;87:929-45.

3. Clark GM, Kranz HG, Nathar JM. Histopathological find ings in cochlear implants in cats. J Laryngol Otol 1975;89: 495 504 .

4. Clark GM. An evaluation of per-scalar cochlear electrode implantation techniques; an histopathological study. J Laryngol Otol 1977;99:185-99.

5. Franz BH-KG, Clark GM, Bloom DM. Effect of experimentally induced otitis media on cochlear implants. Ann Otol Rhinol Laryngol 1987;96 (in press)

6. Shepherd RK, Clark GM, Pyman BC, Webb RL. Banded intracochlear electrode array: evaluation of insertion trauma in hu- man temporal bones. Ann Otol Rhinol Laryngol 1985;94:55-9.

7. Simmons FB. Permanent intracochlear electrodes in cats, tissue tolerance and cochlear microphonics. Laryngoscope 1967; 77:171-86.

8. Schindler RA, Merzenich MM, White MW, Bjorkroth B. Multielectrode intracochlear implants: nerve survival and stimulation patterns. Arch Otolaryngol 1977;103:691-9.

9. Sutton D, Miller JM, Pfingst BE. Comparison of cochlear histopathology following two implant designs for use in scala tympani. Ann Otol Rhinol Laryngol 1980;89(suppl 66):11-4.

10. Franz BK-HG, Clark GM. Refined surgical technique for insertion of banded electrode array. Ann Otol Rhinol Laryngol 1987; 96(suppl 128):15-7.

11. Clifford AR, Gibson WPR. Anatomy of the round window with respect to cochlear implant surgery. Ann Otol Rhinol Laryngol 1987;96(suppl 128):17-9 


\section{University Library}

\section{- M M I N E R VA A gateway to Melbourne's research publications}

Minerva Access is the Institutional Repository of The University of Melbourne

Author/s:

Clark, Graeme M.;Pyman, B. C.;Webb, R. L.;Franz, B. K-H. G.;Redhead, T. J.;Shepherd, R. K.

Title:

Surgery for the safe insertion and reinsertion of the banded electrode array

Date:

1987

Citation:

Clark, G. M., Pyman, B. C., Webb, R. L., Franz, B. K. G., Redhead, T. J., \& Shepherd, R. K. (1987). Surgery for the safe insertion and reinsertion of the banded electrode array. Annals of Otology, Rhinology \& Laryngology, January-February, 96(1, part 2, suppl.128), 10-12.

Persistent Link:

http://hdl.handle.net/11343/27243 